\title{
Research Paper: The Relationship Between Personality Characteristics and Early Maladaptive Schema With Suicide Ideation in Iranian Late Adolescents
}

\author{
Ahmad Valikhani ${ }^{*}$, Abdolaziz Aflakseir ${ }^{1}$, Razieh Hashemi ${ }^{1}$, Majdoddin Fathi ${ }^{2}$, Hossein Momeni ${ }^{3}$, Zahra Abbasi ${ }^{4}$ \\ 1. Department of Clinical Psychology, School of Education and Psychology, Shiraz University, Shiraz, Iran. \\ 2. Department of Psychiatry, Research Center for Psychiatry and Behavior Sciences, Shiraz University of Medical Sciences, Shiraz, Iran. \\ 3. Department of General Psychology, Faculty of Literature and Humanity Sciences, Imam Khomeini International University, Qazvin, Iran. \\ 4. Department of Psychology, Faculty of Humanities and Social Sciences, Science and Research Branch, Islamic Azad University, Tehran, Iran.
}

\section{Article info:}

Received: 23 Mar. 2017

Accepted: 10 Jul. 2017

\section{Keywords:}

Five-Factor Model of Personality, Early maladaptive schema, Suicide ideation, Iranian late adolescents
Cftation: Valikhani, A., Aflakseir, A., Hashemi, R., Fathi, M., Momeni, H., \& Abbasi, Z. (2017). The Relationship Between Personality Characteristics and Early Maladaptive Schema With Suicide Ideation in Iranian Late Adolescents. Journal of Practice in Clinical Psychology, 5(4), 271-280. https://doi.org/10.29252/nirp.jpcp.5.4.271

https://doi.org/10.29252/nirp.jpcp.5.4.271 
and university life (Eaton et al., 2008; Suicide Prevention Resource Center, 2012).

Since suicide ideation undergoes a gradual and continuous evolutionary process, starting from thoughts to plans and culminating in suicide (Bertolote et al., 2005); hence, for prevention of suicide, the need to identify thoughts takes priority. So, given the significance of suicide ideation leading to attempt of suicide and its high prevalence rates in adolescents, it is crucial to examine and detect related factors in this population. Meanwhile, Blüml et al. (2013) emphasized the role of personality traits on suicide ideation and behaviors related to suicide. This point has been confirmed in many other research works. Moreover, studies showed that neuroticism, psychoticism, and extraversion are also associated with suicide ideation (Robbins \& Francis, 2009; Singh \& Lal Joshi, 2008).

The relationship between suicide ideation and the FiveFactor Model of personality (FFM) has been extensively investigated. Studies have indicated that neuroticism is positively (Vrshek Schallhorn, Czarlinski, Mineka, Zinbarg, \& Craske, 2011; Chioqueta \& Stiles, 2005), extraversion is negatively (Vrshek Schallhorn et al., 2011), openness positively (Blüml et al., 2013), and conscientiousness are negatively (Velting, 1999) correlated with suicide ideation. Also, Kerby (2003) suggested a model in which suicide ideation increased with high neuroticism, low extraversion, low agreeableness, and low conscientiousness.

On the other hand, studies have investigated the role of Early Maladaptive Schemas (EMSs) on suicide ideation. In one research, it was demonstrated that negative schemas and less positive schemas in the group with suicide ideation were more common than the group with nonsuicide ideation (Fialko et al., 2006). The results of a study on 137 patients with post-traumatic stress disorder indicated that social isolation/alienation, defectiveness/ shame, failure, dependence/incompetence, subjugation of needs, emotional inhibition, and unrelenting standards schemas were linked with suicide ideation; while social isolation/alienation, defectiveness/shame, failure, dependence/incompetence, and enmeshment schemas were correlated with suicide plan; also defectiveness/shame and failure schemas were related to suicide attempt (Dutra, Callahan, Forman, Mendelsohn, \& Herman, 2008).

Another study found that there were significant differences in the EMSs scores in depressed patients with suicide attempt, depressed patients with non-suicide attempt, and non-clinical patients; so that, there was a dif- ference in all the EMSs between two clinical groups and non-clinical group. However, two clinical groups were significantly different in just three schemas, emotional deprivation, dependence/incompetence, and vulnerability to harm or illness (Ahmadian Gorji, Fata, Asgharnejad Farid, \& Malakoti, 2009).

Taken together, the personality traits and early maladaptive schemas play an important role in suicide ideation. There are some theories and studies that have considered the relationships between EMSs and the FFM concepts. And they claim that the two concepts considerably overlap with each other. In the Beck model, schema concept in cognitive theory is embedded in personality. Personality is described as a field of practice in cognitive, emotional, motivational, behavioral, and physiological systems. Each system has been composited with particular schemas. So, different categories of schemas are identified: cognitive schemas are creditworthy for information processing; emotional schemas create feelings; categories of motivational and behavioral schemas launch the readying or prohibition of act; physiological schemas include activating the autonomic nervous system and the motor or sensory systems (Beck, 1996). Thus, it seems there is a component to the whole relationship between EMSs and personality; And in cognitive theory of personality, personality has been established from schemas in various domains of cognitive, motivational, behavioral, and physiological systems.

Additionally, research has shown an overlap between FFM and the EMSs; For example, Sava (2009) examined the relationship between the FFM and EMSs in university students and found that there were significant links between personality traits and most of the EMSs, especially with neuroticism and agreeableness. Moreover, results of Cannon correlation indicated that the first function was formed by the relationship of neuroticism and agreeableness with EMSs; low agreeableness and high neuroticism have been linearly linked with all the EMSs, especially with schema related to disconnection and rejection and impaired boundaries domains, with the exception of social undesirability schema (Sava, 2009).

Muris (2006) carried out a study in non-clinical adolescents aged 12 to 15 years and found that neuroticism was extensively related to EMSs; Extraversion was only correlated with unrelenting standards schema; agreeableness was linked with self-sacrifice and unrelenting standards schemas; and Openness correlated with vulnerability to harm/illness. The study by Thimm (2010) also corroborated that there was a high overlap between EMSs and facets of the FFM. 
According to the relationship between EMSs and the FFM, a question is raised that whether both the fivefactor model of personality and the early maladaptive schemas equally predict suicide ideation, whether they have the same concept and significance in this field or do schema play a more important role as a predictor of suicide ideation as compared with the FFM. Although, this question is also considered by some researchers in other areas of psychopathology; For example, Thimm (2010) in his study found that EMSs had significantly 11 percent incremental variance on depression symptoms when controlled for the FFM. Thus, the purpose of the present study is twofold. The first aim is the prediction of suicide ideation by the total EMSs scores beyond the FFM dimensions and demographic variables in adolescents in order to examine incremental variance of the EMSs; the second aim is to investigate the prediction of suicide ideation by schema domains controlling the FFM traits and demographic variables.

\section{Methods}

A total of 315 adolescents (160 female, 155 male) were recruited from third-grade high school students of Shiraz city in Iran. The mean age of the sample was 16.88 years $(\mathrm{SD}=0.61)$, ranging from 16 to 19 years. The mean economic status of the sample was $n=219$ with a high $(n=65)$, and low $(n=28)$ economic status, respectively. Ethnic groups of participants were as following: Just over 186 of students were Fars, 49 students were Lur, 23 students were Turk, 3 students were Kurd, and 53 students rated themselves as "other". Also, one student had not mentioned his or her ethnicity.

The study was approved by the local ethics committee. All students were informed that participation was voluntary, and their informed consent was taken before the start of the study. They were also told that there was no concept of right or wrong answers and that their information would be kept confidential. Questionnaire completion took approximately 65 minutes per participant. The measures used were NEO Five-Factor Inventory (NEO-FFI; Costa \& McCrae, 1992), Schema Questionnaire-Short Form (SQ-SF; Young \& Brown, 1999), and Beck Scale for Suicidal Ideation (BSSI) (Beck \& Steer, 1991).

NEO Five-Factor Inventory is a 60-item self-report instrument designed to assess Neuroticism (N), Extraversion (E), Openness to experience (O), Agreeableness (A), and Conscientious (C). Items are rated on a 5-point scale ranging from 1 (strongly disagree) to 5 (strongly agree). The original NEO-FFI has high internal consistency levels, good test-retest reliabilities as well as con- vergent and discriminant validity and the translations available in several idioms are also psychometrically sound (Costa \& McCrae, 1992). In this study, we used the Iranian translation of the NEO FFI. The Iranian version of the NEO FFI has shown a relatively good reliability and validity except for O (Anisi, Majdiyan, Joshanloo, \& Ghoharikamel, 2011). Anisi et al. (2011) in their study in military students showed that the convergence validity between neuroticism and extraversion of the NEO FFI and neuroticism and extraversion of the Eysenck personality questionnaire was 0.68 and 0.47 , respectively. Also, Cronbach's alpha for $\mathrm{C}$ was 0.83 , for $\mathrm{N}$ was 0.80 , for $\mathrm{A}$ was 0.60 , for $\mathrm{E}$ was 0.58 , and for $\mathrm{O}$ was low 0.39 . In the present study, internal consistency for the sub-scales was $\mathrm{N}=82, \mathrm{E}=79, \mathrm{O}=60, \mathrm{~A}=69$, and $\mathrm{C}=75$.

The short form of the SQ-SF was used to measure EMSs and its five domains. This scale included 75 items on 6-points Likert-type ( $1=$ completely untrue of me, $6=\mathrm{de}$ scribe me perfectly). This scale was used to assess 15 EMSs on 5 domains. Young \& Brown (1999) have shown that the inventory has adequate internal consistency and factorial structure. Ghiasi (2011) translated it and studied psychometric properties in Iranian population. They found that convergent validity coefficient was 0.64 for the total EMSs and inefficient attitudes scale. Cronbach's alpha for five domains was in order of increasing magnitude, 0.90 for disconnection and rejection, 0.84 for impaired autonomy and performance, 0.81 for over-vigilance and inhibition, 0.76 for other-directedness, and 0.68 for impaired limits, and 0.94 for the total scale. In the present study, internal consistency for the sub-scales was 0.82 for disconnection and rejection, 0.76 for impaired autonomy and performance, 0.79 for over-vigilance and inhibition, 0.66 for other-directedness, and 0.68 for impaired limits and 0.79 for the total scale. These results show that this scale has good reliability and validity in the Iranian population.

BSSI is designed to measure suicide ideation. The BSSI consists of 19 items, and the answers are rated on a 3-point Likert Scale. The internal reliability, test-retest stability and concurrent validity of this self-report measure has been established as well (Beck \& Steer, 1991). In Iran, Anisi, Fathi Ashtiani, Salimi, and Ahmadi (2005) have carried out the study using this scale in soldiers, in order to find its psychometric properties. They found that its convergent validity with depression and general health questionnaires was 0.76 and 0.57 , respectively. Additionally, its Cronbach's alpha was excellent 0.95 . In the present study, internal consistency for the scale was 0.83 .

This study was carried out in eight high schools in Shiraz city. Multi-stage cluster sampling was used to deter- 
mine the study participants. From a list of all the female and male high schools, two high schools (one female school, one male school) from the quadruple areas of city were chosen. Thus, taken together, 8 high schools, were randomly recruited. Subsequently, two classes from third grade in selected schools were randomly recruited. Finally, the questionnaires were distributed among students in order to complete them.

For statistical analysis, first, we examined the mean and standard deviation of variables (Table 1). Then, we used zero-order correlations of suicide ideation with the Big Five personality traits and the early maladaptive schema, which are presented in Table 1. Prior to that, distribution of all the variables was examined for normality, skewness (variables were not skewed) and kurtosis (-2 to 2). A hierarchical regression analysis was used to examine whether the total score of early maladaptive schemas adds incremental variance to the prediction of suicide ideation beyond the Big Five personality traits, age and gender (Table 2). Also, in order to test the second hypothesis that which one of the EMS domains would predict the suicide ideation controlling for FFM, age and gender, hierarchical regression analysis was used (Table 3).

\section{Results}

The results of zero-order correlations are demonstrated in Table 1. The results of zero-order correlations between suicide ideation and FFM dimensions indicated that suicide ideation was positively correlated with neuroticism, and negatively linked with extraversion, agreeableness, and conscientiousness, but it did not have any significant correlation with openness. There was a positive and significant correlation between suicide ideation and the total score of EMSs. Additionally, suicide ideation was positively and significantly correlated with disconnection and rejection, impaired autonomy and performance, other-directedness, over-vigilance and inhibition, and impaired limits. Moreover, there was a significant correlation between suicide ideation with gender and age. The mean scores of conscientiousness personality and domain of disconnection and rejection were higher in this sample than other variables.

A hierarchical regression analysis was used to predict suicide ideation by the EMSs total score. To do so, in the first step the demographic variables were entered as a block in the regression. Next, in the second step, the FFM dimensions were entered. Finally, in the third step, the EMSs total score was entered. The results that were presented in Table 2 showed that the EMSs total score accounting for $2 \%(\mathrm{P}<0.01)$ of the variance in suicide ideation when controlled for the FFM dimensions and gender and age. Also, the EMSs total score significantly predicted $(\beta=0.20, \mathrm{P}=0.003)$ suicide ideation.

Results of prediction of suicide ideation by EMS domains controlling for the FFM dimensions and demographic variables are presented in Table 3 . The results of hierarchical regression analysis showed that two out of five domains could significantly predict suicide ideation (step 3) in controlled demographic variables (step 1) and the FFM dimensions (step 2). So that, domains of disconnection and rejection negatively $(\beta=0.25, \mathrm{P}=0.003)$, and over vigilance and inhibition positively and significantly $(\beta=-0.17, \mathrm{P}=0.011)$ predicted suicide ideation.

\section{Discussion}

The purpose of the current study was the prediction of suicide ideation by EMSs controlling for personality traits and demographic variables. The results demonstrated that the EMSs total score had incremental variance in suicide ideation beyond the FFM dimensions and demographic variables. Additionally, among the five EMS domains, only two domains namely disconnection and rejection, and over-vigilance and inhibition significantly predicted suicide ideation.

The present study shows that the EMSs total score significantly predicted suicide ideation beyond the FFM dimensions, age, and gender. The previous study had showed that EMSs were positively and significantly linked with suicide ideation (e.g. Dutra, Callahan, Forman, Mendelsohn, \& Herman, 2008). This result confirmed the claim of Young, Klosko, and Weishaar (2003) that mentioned EMSs are self-destructive, affective and cognitive patterns and cause significant functional impairments during life. According to this finding, it can be said that the schema therapy plays an important role in the prevention and treatment of suicide ideation. In fact, the result shows that EMSs are beyond personality in predicting suicide ideation, although, the effect is minimal $(2 \%)$.

Thimm (2010) in his study demonstrated that EMSs significantly predicted depression symptoms when controlled for the FFM. These findings indicated that there is a high correlation between EMSs and FFM dimensions. However, EMSs have shown the unique effect in psychological impairments. Subsequently, we can conclude that the EMSs and personality concepts are at least and partly independent of each other. However, there are a few studies in this area; this claim should be supported by other studies. Future researches should study the rela- 

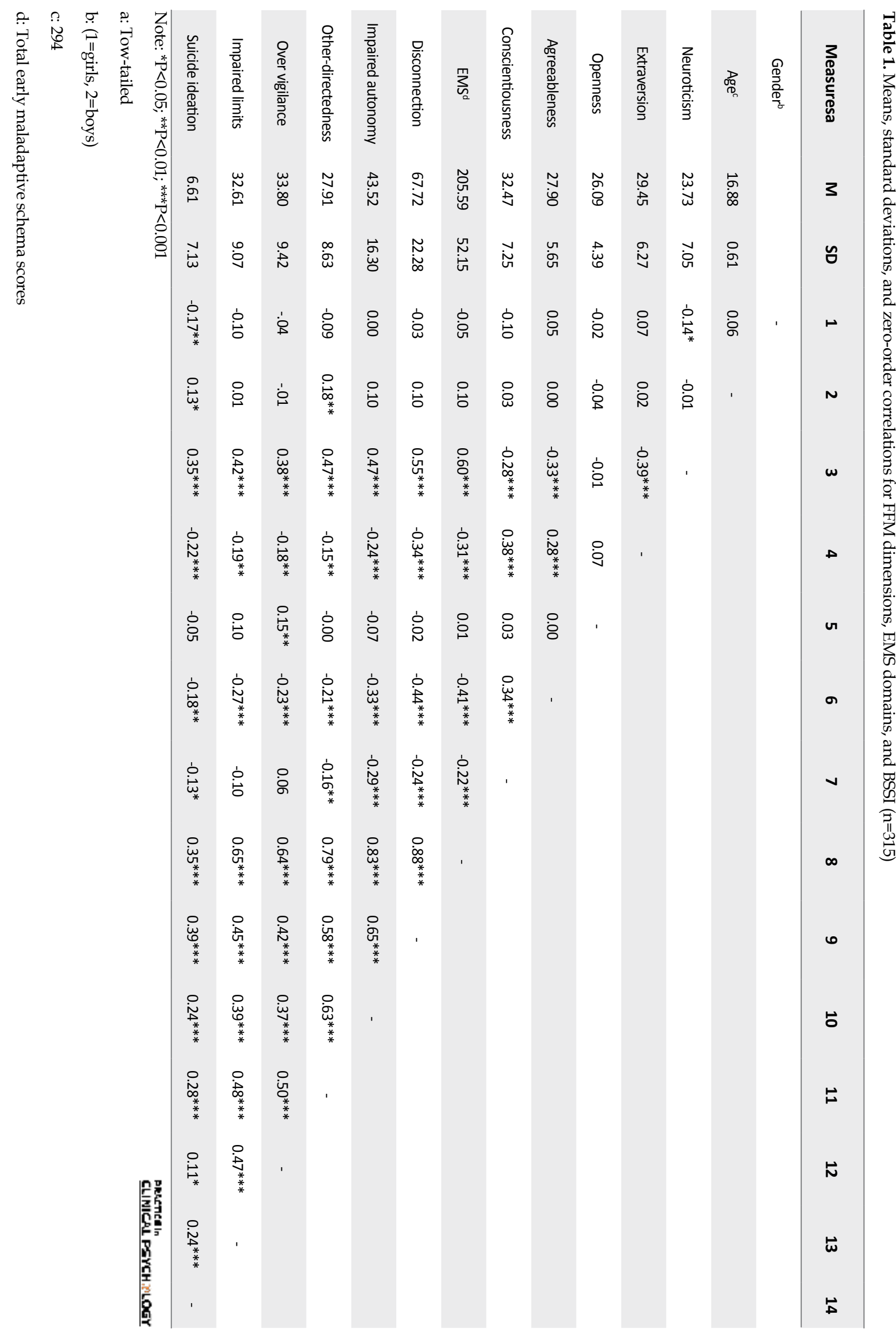
Table 2. Results of hierarchical regression analysis for predicting suicide ideation by the EMSs total score controlling for the FFM dimensions and demographic variables

\begin{tabular}{|c|c|c|c|c|c|c|}
\hline Steps & Predictors & $\Delta \mathbf{R}^{2}$ & $\Delta \mathrm{F}^{\mathrm{a}}$ & Total $_{\text {adj }} \mathbf{R}^{2}$ & $\beta$ & $\mathbf{P}$ \\
\hline \multirow{3}{*}{1} & Gender & & & & -0.19 & 0.001 \\
\hline & & 0.05 & $8.52^{* *}$ & 0.04 & & \\
\hline & Age & & & & 0.14 & 0.013 \\
\hline \multirow{7}{*}{2} & Gender & & & & -0.14 & 0.008 \\
\hline & Age & & & & 0.14 & 0.007 \\
\hline & Neuroticism & & & & 0.29 & 0.0001 \\
\hline & Extraversion & 0.13 & $9.61^{* *}$ & 0.17 & -0.09 & 0.139 \\
\hline & Openness & & & & -0.05 & 0.310 \\
\hline & Agreeableness & & & & -0.04 & 0.497 \\
\hline & Conscientiousness & & & & -0.01 & 0.776 \\
\hline \multirow{9}{*}{3} & Gender & & & & -0.15 & 0.005 \\
\hline & Age & & & & 0.12 & 0.023 \\
\hline & Neuroticism & & & & 0.19 & 0.007 \\
\hline & Extraversion & & & & -0.08 & 0.187 \\
\hline & & 0.02 & $8.11^{*}$ & 0.19 & & \\
\hline & Openness & & & & -0.05 & 0.273 \\
\hline & Agreeableness & & & & 0.00 & 0.893 \\
\hline & Conscientiousness & & & & -0.02 & 0.687 \\
\hline & ESM & & & & 0.20 & 0.005 \\
\hline
\end{tabular}

tionship between EMSs and FFM dimensions in relation to other psychopathological variables such as anxiety, stress, and especially personality disorders, so that, the relationship between two concepts become more clear and also to provide some important implications for the action mechanism of EMSs.

Hierarchical regression analysis found that two out of five EMS domains had significantly predicted suicide ideation with controlled FFM dimensions, gender, and age, disconnection and rejection and over-vigilance and inhibition (positively and negatively, respectively). Previous researches have shown that schemas of disconnection and rejection among other schemas have been more efficient in predicting suicide ideation (Dutra et al., 2008; Ahmadian Gorji et al., 2009), depression (Renner, Lobbestael, Peeters, Arntz, \& Huibers, 2012) and neuroticism (Sava, 2009) that they are directly linked with suicide ideation. Thus, it can be concluded that the disconnection and rejection domain is a better predictor of suicide ideation than other domains. Moreover, according to the definitions of five domains, it can be inferred that disconnection and rejection domain that includes the schemas which an individual needs for security and acceptance, are not met in a predictable way. It can be expected that if certain needs like security and acceptance, protection, and empathy, that are fundamental components of life are not met, a person would be more vulnerable to other problems and impairments.

Considering the interesting result of the negative relationship between over-vigilance, inhibition domain and suicide ideation, it can be said that as it was shown in previous research that over-vigilance and inhibition domain were negatively correlated with depression (Renner et al., 2012), the operation mechanism of this domain is differentiated between other domains and schemas.

Since people who have this kind of schemas have been excessively emphasized upon for controlling their own 
Table 3. Results of hierarchical regression analysis for predicting suicide ideation by the EMS domains controlling for the FFM dimensions and demographic variables

\begin{tabular}{|c|c|c|c|c|c|}
\hline Steps & Predictors & $\Delta \mathbf{F}^{\mathrm{a}}$ & Total $_{\text {adj }} \mathbf{R}^{2}$ & $\beta$ & p \\
\hline \multirow{3}{*}{1} & Gender & & & -0.19 & 0.001 \\
\hline & & $8.52^{* * *}$ & 0.04 & & \\
\hline & Age & & & 0.14 & 0.013 \\
\hline \multirow{7}{*}{2} & Gender & & & -0.14 & 0.008 \\
\hline & Age & & & 0.14 & 0.007 \\
\hline & Neuroticism & & & 0.29 & 0.0001 \\
\hline & Extraversion & $9.61 * * *$ & 0.17 & -0.09 & 0.139 \\
\hline & Openness & & & -0.05 & 0.310 \\
\hline & Agreeableness & & & -0.04 & 0.497 \\
\hline & Conscientiousness & & & -0.01 & 0.776 \\
\hline \multirow{13}{*}{3} & Gender & & & -0.13 & 0.012 \\
\hline & Age & & & 0.09 & 0.075 \\
\hline & Neuroticism & & & 0.18 & 0.008 \\
\hline & Extraversion & & & -0.09 & 0.139 \\
\hline & Openness & & & -0.03 & 0.466 \\
\hline & Agreeableness & & & 0.02 & 0.740 \\
\hline & & $4.65 * * *$ & 0.22 & & \\
\hline & Conscientiousness & & & 0.01 & 0.806 \\
\hline & Disconnection & & & 0.25 & 0.003 \\
\hline & Impaired autonomy & & & -0.05 & 0.508 \\
\hline & Other-directedness & & & 0.11 & 0.161 \\
\hline & Over vigilance & & & -0.17 & 0.011 \\
\hline & Impaired limits & & & 0.09 & 0.150 \\
\hline
\end{tabular}

beliefs, feelings, and behaviors (Young \& Brown, 1999), it may cause them to drive unwanted thoughts and feelings (such as, suicide ideation) temporarily out of their own consciousness. Thus, these people may be unable to express their own negative emotions. This can probably be effective as a short term coping mechanism, but it may as act as an important vulnerable factor in the long term. Future research should consider this also study the cause of negative relationship between over-vigilance and inhibition and some psychopathological variables.

In fact, schema therapy addresses the core psychological issues that are substantial in patients with character disorders. These core issues are called core maladaptive schemas. Besides, schema therapy is also appropriate for the treatment of axis I and II disorders that have substantial theme in their own lifetime. Schema therapy is also designed to treat chronic character psychopathology rather than acute psychiatric symptoms (Young, Klosko, \& Weishaar 2003). Young, Klosko, and Weishaar (2003) defined early maladaptive schemas that are as broad, pervasive themes regarding oneself and one's relationships with others, that are dysfunctional to a crucial degree. Also, they defined it as affective and cognitive patterns of self-destructive that developed during childhood or adolescence and expanded throughout one's lifetime. 
However, schema therapy is established based upon the change in the early maladaptive schema.

Since Freud, personality has been identified as a structure that starts forming from childhood, and the psychopathology is born from that. Besides, the trait psychologists in the area of personality psychology have also emphasized the role of biology in personality (McCrae $\&$ Costa, 2003). By accepting one of these approaches in pathology, it will cause disappointment of change. But the new schema therapy approach to the personality is promising. Since schema approach claims that personality is made from several schemas in variety area (Beck, 1996), schema is changeable, and there is a hope that schema therapy can change components of personality (schemas) that can result in changing at least some part of personality or the entire personality. However, this claim needs further researches.

The result of the current study highlights that schema therapy can specifically work upon disconnection and rejection schemas so as to prevent or treat suicide ideation in adolescents rather than work on the all the schemas that would not be so time effective and cost effective However, since over-vigilance and inhibition domain had negatively predicted suicide ideation, we cannot simply give a direct order in relation to increase of these schemas in adolescents, because the nature of the schemas are maladaptive and can cause crucial dysfunction in one's lifetime (Young, Klosko, \& Weishaar 2003). Thus, it can be said that over-vigilance and inhibition domains are led to suppress one's feelings and thoughts, which are not emerged consciously, so it has no effect on one's answer in the pencil-paper test, but it may cause other problems in future.

The current study has some limitations that should be taken into consideration. According to the relationship between depression (Zhang \& Tao, 2013) and anxiety (Fialko et al., 2006), and suicide ideation, it is necessary for the future study to control them. Additionally, this study was carried out in healthy adolescent population, so future studies can consider researching this topic in clinical adolescents.

\section{Acknowledgements}

The authors would like to thank all students who participated in this research. This research did not receive any specific grant from funding agencies in the public, commercial, or not-for-profit sectors.

\section{Conflict of Interest}

All authors certify that this manuscript has neither been published in whole nor in part nor being considered for publication elsewhere. The authors have no conflicts of interest to declare.

\section{References}

Ahmadian Gorji, M., Fata, L., Asgharnejad Farid, \& Malakoti, S K. (2009). [A comparison of the early maladaptive schemas of suicidal and non-suicidal depressed patients with non-clinical sample (Persian)]. Advances in Cognitive Science, 10(4), 49-59.

Anisi, J., Fathi, A. A., Salimi, S., \& Ahmadi, N. K. (2005). [Validity and reliability of Beck suicide scale ideation among soldiers (Persian)]. Journal of Military Medicine, 7(1), 33-37.

Anisi, J., Majdiyan, M., Joshanloo, M., \& Ghoharikamel, Z. (2011). [Validity and reliability of NEO Five-Factor Inventory (NEO-FFI) on university students (Persian)]. International Journal of Behavioral Sciences, 5(4), 351-355.

Beck, A. T. (1996). Beyond belief: A theory of modes, personality, and psychopathology. In P. M. Salkovskis (Ed.), Frontiers of Cognitive Therapy (pp. 1-25). New York: Guilford.

Beck, A. T., \& Steer, R. A. (1991). Manual for the Beck scale for suicide ideation. San Antonio, TX: Psychological Corporation.

Bertolotei, J. M., Fleischmanni, A., De Leo, D., Bolhari, J., Botega, N., De Sil, D., et al. (2005). Suicide attempts, plans, and ideation in culturally diverse sites: The WHO SUPRE-MISS community survey. Psychological Medicine, 35, 1457-65. doi: 10.1017/S0033291705005404

Blüml, V., Kapusta, N. D., Doering, S., Brähler, E., Wagner, B., \& Kersting, A. (2013). Personality factors and suicide risk in a representative sample of the German general population. PloS ONE, 8(10), e76646. doi: 10.1371/journal.pone.0076646

Chioqueta, A. P., \& Stiles, T. C. (2005). Personality traits and the development of depression, hopelessness, and suicide ideation. Personality and Individual Differences, 38(6), 1283-1291. doi: $10.1016 /$ j.paid.2004.08.010

Costa, P. T., \& McCrae, R. R. (1992). Revised NEO Personality Inventory: Professional manual. Odessa, Florida: Psychological Assessment Resources.

Dutra, L., Callahan, K., Forman, E., Mendelsohn, M., \& Herman, J. (2008). Core schemas and suicidality in a chronically traumatized population. Journal of Nervous and Mental Disease, 196, 71-74. doi: 10.1097/NMD.0b013e31815fa4c1

Eaton, D. K., Kann, L., Kinchen, S., Shanklin, S., Ross, J., Hawkins, J., et al. (2008). Youth risk behavior surveillance-United States, 2007. MMWR Surveill Summ, 57(4), 1-131.

Fialko, L., Freeman, D., Bebbington, P. E., Kuipers, E., Garety, P. A., Dunn, G., et al. (2006). Understanding suicidal ideation in psychosis: findings from the Psychological Prevention of Relapse in Psychosis (PRP) trial. Acta Psychiatrica Scandinavica, 114(3), 177-86. doi: 10.1111/j.1600-0447.2006.00849.x 
Ghiasi, M. (2011). [Normalization, validation and reliability of the Young Schema Questionnaire (third version of short form) in two groups of normal individuals and patients with mental disorders in Tehran (MSc. thesis) (Persian)]. Isfahan: Isfahan University.

Kay, N. S., Jantaraweragul, S., Kanungsukkasem, V., Li, K., Jones, M. R., \& Huang, Y. (2012). Suicide ideation associations with attitudes toward suicide, quality of life, and attitudes toward death and dying among Chinese, Korean, Thai, and Vietnamese high school seniors. Journal of Education and Learning, 1(2), 192

Kerby, D. S. (2003). CART analysis with unit-weighted regression to predict suicidal ideation from Big Five traits. Personality and Individual Differences, 35(2), 249-261. doi: 10.1016/S0191$8869(02) 00174-5$

Kjøller, M., \& Helweg-Larsen, M. (2000). Suicidal ideation and suicide attempts among adult Danes. Scandinavian Journal of Public Health, 28(1), 54-61. PMID: 10817315

McCrae, R. R., \& Costa, P. T. (2003). Personality in adulthood: A five-factor theory perspective, ( $2^{\text {nd }} \mathrm{Ed}$.). New York: Guilford Press.

Muris, P. (2006). Maladaptive schemas in non-clinical adolescents: Relations to perceived parental rearing behaviours, big five personality factors and psychopathological symptoms. Clinical Psychology \& Psychotherapy, 13, 405-13.

Muula, A. S., Kazembe, L. N., Rudatsikira, E., \& Siziya, S. (2007) Suicidal ideation and associated factors among in-school adolescents in Zambia. Tanzania Journal of Health Research, 9(3), 202-206. PMID: 18087900

Nicholson, S., Jenkins, R., \& Meltzer, H. (2009). Suicidal thoughts, suicide attempts and self-harm. In McManus, S., Meltzer, H. Brugha, T. S., Bebbington, P. E., \& Jenkins, R. (Eds.). Adult Psychiatric Morbidity in England, 2007: Results of a Household Survey (pp. 71-87). London: The NHS Information Centre for health and social care.

Renner, F., Lobbestael, J., Peeters, F., Arntz, A., \& Huibers, M. (2012). Early maladaptive schemas in depressed patients: Stability and relation with depressive symptoms over the course of treatment. Journal of Affective Disorders, 136(3), 581-590. doi: 10.1016/j.jad.2011.10.027

Robbins, M \& Francis, L. J. (2009). The spiritual revolution and suicidal ideation: an empirical enquiry among 13- to 15-year-old adolescents in England and Wales. International Journal of Children's Spirituality, 14(3), 261-272. doi: $10.1080 / 13644360903086539$

Sava, F. A. (2009). Maladaptive schemas, irrational beliefs, and their relationship with the five-factor personality model. Journal of Cognitive and Behavioral Psychotherapies, 9, 135-147.

Singh, R., \& Joshi, H. L. (2008). Suicidal ideation in relation to depression, life stress and personality among college students. Journal of the Indian Academy of Applied Psychology, 34(2), 259265.

Suicide Prevention Resource Center [SPRC]. (2012). Glossary [Internet]. Retrieved from: http://www.sprc.org/basics/ glossary

Thimm, J. C. (2010). Personality and early maladaptive schemas: A five-factor model perspective. Journal of Behavior Therapy and Experimental Psychiatry, 41, 373-380.
Velting, D. M. (1999). Suicidal ideation and the five-factor model of personality. Personality and Individual Differences, 27, 943952. doi: 10.1016/S0191-8869(99)00046-X

Vrshek-Schallhorn, S., Czarlinski, J., Mineka, S., Zinbarg, R. E. \& Craske, M. (2011). Prospective predictors of suicidal ideation during depressive episodes among older adolescents and young adults. Personality and Individual Differences, 50(8), 12021207. doi: 10.1016/j.paid.2011.02.008

Weissman, M. M., Bland, R. C., Canino, G. J., Greenwald, S., Hwu, H. G., Joyce, P. R., et al. (1999). Prevalence of suicide ideation and suicide attempts in nine countries. Psychological Medicine, 29(1), 9-17. PMID: 10077289

Young, J. E. (1999). Cognitive therapy for personality disorders: A schema-focused approach, ( $3^{\text {rd }}$ Ed.). Sarasota, Florida: Professional Resource Press.

Young, J. E., \& Brown, G. (1999). Young Schema Questionnaire. In J. E. Young, Cognitive Therapy for Personality Disorders: A Schema-Focused Approach (3 ${ }^{\text {rd }}$ Ed.) (pp. 59-68). Sarasota, Florida: Professional Resource Press.

Young, J. E., Klosko, J. S., \& Weishaar, M. E. (2003). Schema therapy: A practitioner's guide. New York: Guilford Press.

Zhang, J., \& Tao, M. (2013). Relative deprivation and psychopathology of Chinese college students. Journal of Affective Disorders, 150(3), 903-07. doi: 10.1016/j.jad.2013.05.013

Zhang, J., Stewart, R., Phillips, M., Shi, Q., \& Prince, M. (2009). Pesticide exposure and suicidal ideation in rural communities in Zhejiang province, China. Bulletin of the World Health Organization, 87(10), 745-753. 
